\title{
Effects of Nano-Lubricants on Power and CO Emission of a Diesel Engine: An Experimental Investigation
}

\author{
Ali Can Yılmaz* \\ Çukurova University, Adana Vocational School of Higher Education, Department of Motor Vehicles and \\ Transportation Technologies, Adana, Turkey \\ *acyilmaz@cu.edu.tr
}

Received: 15 August 2018

Accepted: 13 September 2019

DOI: $10.18466 /$ cbayarfbe. 453763

\begin{abstract}
In this study, it was aimed to investigate the effects of copper (II) oxide $(\mathrm{CuO})$, copper zinc iron oxide $\left(\mathrm{CuZnFe}_{2} \mathrm{O}_{4}\right)$ and copper iron oxide $\left(\mathrm{CuFe}_{2} \mathrm{O}_{4}\right)$ nanoparticle additives in synthetic diesel engine oil $(5 \mathrm{~W}-$ $40)$ at the fraction of $0.08 \mathrm{wt} \%$ on friction and wear in piston ring-cylinder liner mechanism of the engine. In this regard, Scanning Electron Microscope (SEM) analyses of the nanoparticles were first carried out and via a linear reciprocating tribometer, friction coefficients were determined on specimens comprised of the same material with real engine piston ring. Subsequently, SEM analyses of the samples exposed to abrasion were carried out to investigate the wear characteristics. In the second stage of the experimental study, oil sump of the diesel test engine was filled with raw oil (oil without nano additives) and prepared nano oils (oil+nano additives) separately to unravel the effects of the lubricants on engine power and carbon monoxide (CO) emissions. According to the results, it was determined that $\mathrm{CuZnFe} \mathrm{O}_{4}$ nano lubricant was the most pronounced of all in terms of tribological performance, engine power and $\mathrm{CO}$ emissions. The results depicted that, in the best case, an average increment of $15 \%$ in engine power and an average reduction of $18 \%$ in $\mathrm{CO}$ emissions with $\mathrm{CuZnFe} 2 \mathrm{O} 4$ nano oil were provided compared to that of the raw oil.
\end{abstract}

Keywords: Emission, engine oil, nano additive, performance, tribology.

\section{Introduction}

Nano additives in engine lubricants are, in general, known with their good anti-friction, anti-wear and load bearing capacity features [1]. Various mechanisms such as mending effect $[1,2]$, polishing effect [3] and rolling effect [4-7] have been reported. An experimental study [8] has proved that friction between piston and cylinder lining of an internal combustion engine causes approximately $50 \%$ of the total power loss. Similarly, there are several studies merely focusing on tribological interaction between moving parts of the mechanism [914]. However, this study reports the effects of tribological enhancement on CO emissions and power characteristics of the engine which has not been established by other researchers before. Myriad lubrication regimes occur on interaction surfaces and these regimes strongly depend on sliding speed, normal load and oil viscosity [15]. Generally, in high revs, oil pressure between contact surfaces reaches adequate levels to separate the piston and the substrate which also leads to good load bearing capacity (hydrodynamic lubrication). Low revs, high loads and high oil temperatures effecting the viscosity of the oil in large quantities impede necessary tribofilm formation. Maximum metal contact (maximum wear) is expected in case of very thin tribofilm formation. Stribeck and Hersey numbers (Eq.1) are used to characterize the lubrication regimes and tribofilm formation, respectively [8].

$$
S=\frac{\gamma^{*} v_{a}}{F_{n}}
$$

where;

S: Stribeck number, $\gamma$ : dynamic viscosity, $v_{a}$ : average sliding speed, $F_{n}:$ normal load

This experimental study aims to investigate the effects of tribological improvement in power and $\mathrm{CO}$ emission of a diesel engine introduced with various nano lubricants. Ali et.al. [16] conducted a study aiming to reduce the fuel consumption and to increase torque of an engine using $\mathrm{Al}_{2} \mathrm{O}_{3} / \mathrm{TiO}_{2}$ nanomaterials as lubricant additives. Referring to NEDC standards, they reduced the average fuel consumption to an extent of $4 \mathrm{~L} / 100 \mathrm{~km}$. On the other hand, the peak brake power of the engine (on motorway) was improved by $10 \%$ with nano lubricant compared to that of the lubricant without nano particles. In another study, Ali et.al. [17] reported that the actual engine power and torque increased by $7-10 \%$ due to 
lower total frictional power by $6 \%$ as a direct result of improving the anti-friction and anti-wear.

\section{Materials and Methods}

A reciprocating tribometer (oil heater included) with loading capacity between $100 \mathrm{mN}$ and $60 \mathrm{~N}$, load resolution of $30 \mathrm{mN}$, linear speed of $0-140 \mathrm{~mm} / \mathrm{s}$, stroke of 0-35 $\mathrm{mm}$ and maximum frequency of $40 \mathrm{~Hz}$ was utilized for friction analyses. The data were collected by an acquisition system and necessary calculations were conducted by a special software (Figure 1). This test rig was capable of mimicking reciprocating motion of crank mechanism of an internal combustion engine. An electric motor drives the piston and the piston transmits the motion to the liner specimen which is also in contact with the piston ring specimen. The normal load was exerted on the piston ring specimen using weights at the end of the loading arm. All experimental trials were conducted under $20 \mathrm{~N}$ normal load conditions due to excessive abrasion and damaged surface above 20 N. A transducer was utilized to measure the average coefficient of friction (ACOF) between piston ring and the liner specimens which were cut from a real engine $(100 \mathrm{Cr} 6$ steel, app. 62-65 HRC, E=210 GPa, v=0.35). All experiments were conducted in triplicate and averages were taken into account to improve accuracy. Each friction experiment was performed under $1 \mathrm{~m} / \mathrm{s}$ sliding speed, 3 different oil temperature values $\left(50^{\circ} \mathrm{C}, 75^{\circ} \mathrm{C}, 100^{\circ} \mathrm{C}\right)$ conditions for $10 \mathrm{~min}$. For each test, each specimen was submerged in $15 \mathrm{~mL}$ of oil bath. A hydraulic dynamometer connected to a 4-cylinder turbocharged diesel engine (Figure 2) was used to determine the oil effect on engine performance (Table 1). Viscosity measurements (Table 2) were carried out via Saybolt viscosimeter referring to ASTM D445 [18]. The viscometer device has a temperature accuracy of $0.005^{\circ} \mathrm{C}$ and working temperature of $-56^{\circ} \mathrm{C}-105^{\circ} \mathrm{C}$. Raw engine oil (5W-30) was purchased from GEMA and nano particles were purchased from (99.9\% purity) Sigma-Aldrich. Firstly, the nano particles were blended with glycol to prevent oxidizing with air. The nanoparticles were mixed with engine oil using ultrasonic mixer $(0.25 \mathrm{~kW}, 44 \mathrm{kHz})$ for $10 \mathrm{~h}$. Due to substantial sedimentation of nano particles in engine oil above $0.08 \mathrm{wt} \%$, this fraction was used for all experimental trials (Figure 3). No sedimentation was observed in all suspensions comprising $0.08 \mathrm{wt} \%$ nanoparticles even after 5 days. Wear trace visualization analyses (SEM) were conducted on specimens worn under $75^{\circ} \mathrm{C}$ oil temperature (app. engine oil regime temperature). For emission measurement, portable engine exhaust gas analyzer with data acquisition system was utilized which has a accuracy of $\pm 1 \mathrm{ppm}$ for CO. All engine performance and emission experiments were conducted under wide open throttle conditions.

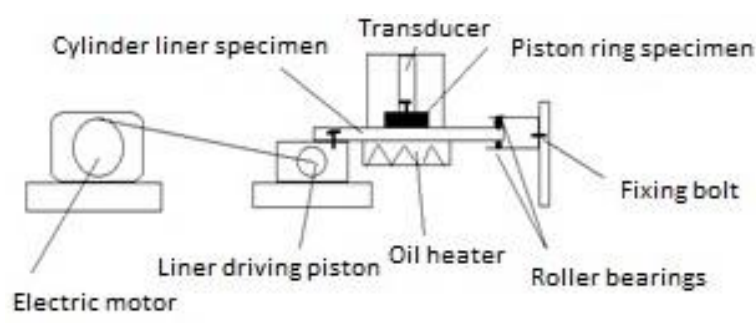

Figure 1. Schematic of the friction test rig.

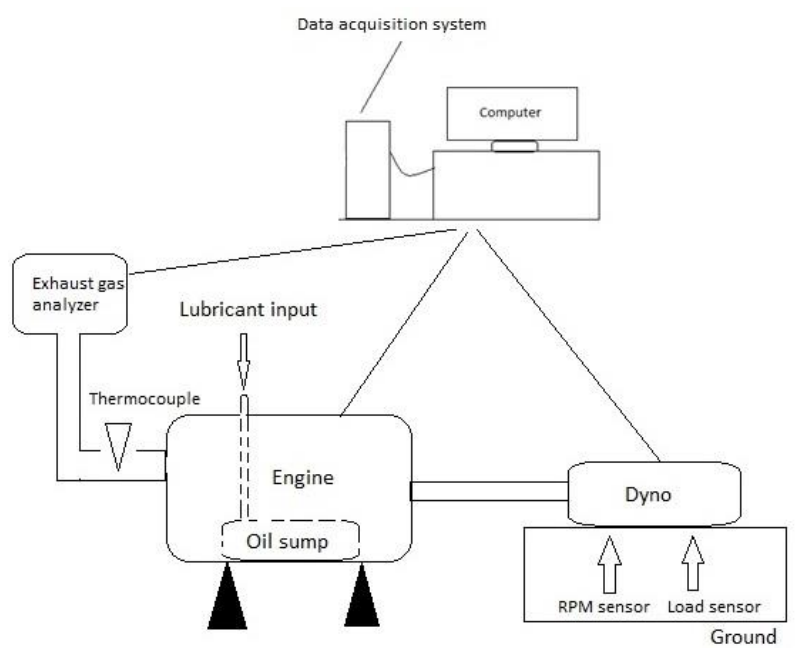

Figure 2. Illustration of the engine test set-up.

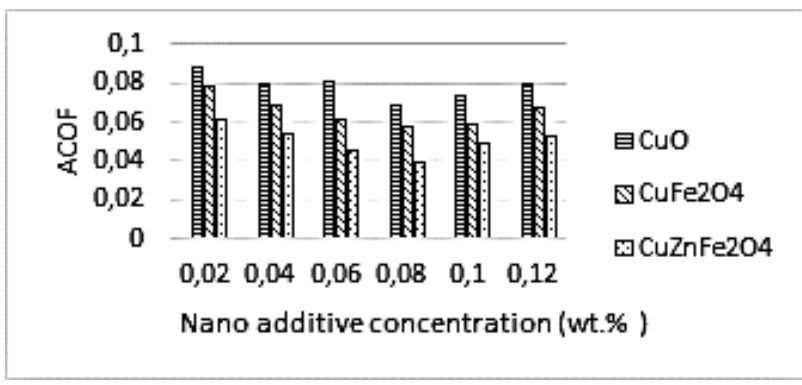

Figure 3. Concentration vs. ACOF.

Table 1. Technical specifications of the test engine.

\begin{tabular}{ll}
\hline Cylinder configuration & Inline/4-cylinder \\
Fuel supply & Direct injection \\
Aspiration & Turbocharged \\
Displacement & $3904 \mathrm{cc}$ \\
Max. power & $100 \mathrm{~kW} @ 2900 \mathrm{rpm}$ \\
Max. torque & $370 \mathrm{Nm} @ 1600 \mathrm{rpm}$ \\
\hline
\end{tabular}

Table 2. Kinematic viscosity measurements $\left(\mathrm{mm}^{2} / \mathrm{s}\right)$.

(1. raw oil, 2. $\mathrm{CuO}$ nano oil, 3. $\mathrm{CuFe}_{2} \mathrm{O}_{4}$ nano oil, 4. $\mathrm{CuZnFe}_{2} \mathrm{O}_{4}$ nano oil)

\begin{tabular}{cccccc}
\hline $\mathbf{T}$ & $\mathbf{1}$ & $\mathbf{2}$ & $\mathbf{3}$ & $\mathbf{4}$ & ASTM D445 \\
\hline $50^{\circ} \mathrm{C}$ & 60.8 & 63.7 & 64.8 & 65.4 & $41.4-74.8$ \\
$75^{\circ} \mathrm{C}$ & 27.5 & 31.3 & 33.5 & 35.2 & $28.8-35.2$ \\
$100^{\circ} \mathrm{C}$ & 14.5 & 17.6 & 19.5 & 22.3 & $12.5-26.1$ \\
\hline
\end{tabular}




\section{Results and Discussion}

\subsection{Friction Analysis}

Nano particle geometry [19] and concentration in engine oil $[20,21]$ are of great importance for tribological performance. According to the results, as the ratio of nanoparticles in the mixture increased, a significant decrease in ACOF was observed in all nano oil environments and at all oil temperatures. However, ratios above $0.08 \mathrm{wt} \%$ caused accumulation of nano particles on the specimen surfaces which led to increased surface roughness and ACOF. The highest ACOF was found for the raw oil and among nano oils, the highest ACOF was found for $\mathrm{CuO}$. According to the SEM analyses, the distribution of $\mathrm{CuO}$ in the oil was not as uniform as the others, which caused local precipitation on the contact surfaces and increased ACOF. Furthermore, the nonspherical geometry of $\mathrm{CuO}$ prevented the rolling effect. SEM images of the nanoparticles (in $500 \mathrm{~nm}$ ) are shown in Figure 4.

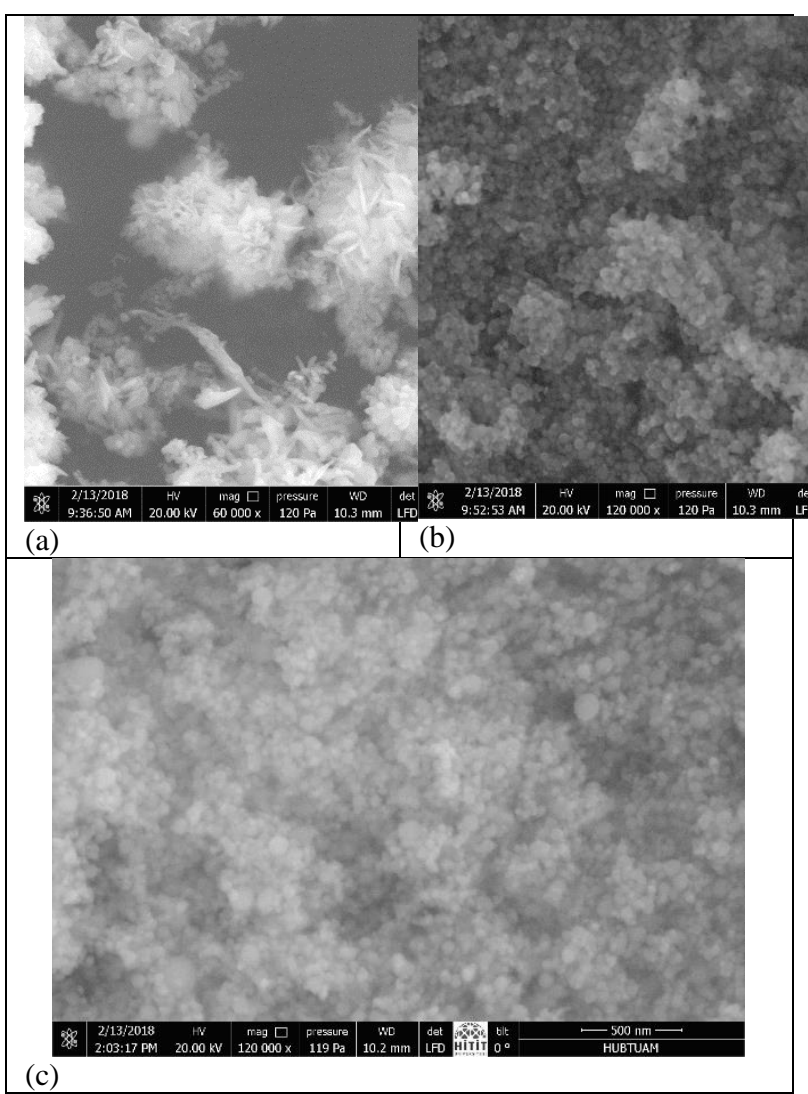

Figure 4. SEM visualization of the nano particles: (a) $\mathrm{CuO}$, (b) $\mathrm{CuFe}_{2} \mathrm{O}_{4}$, (c) $\mathrm{CuZnFe}_{2} \mathrm{O}_{4}$

On the other hand, ACOF highly depends on oil temperature and viscosity. In general, as the temperature decreases viscosity increases. There is a direct proportion between Stribeck number and the viscosity for the same load and sliding speed conditions. High viscosity (@50 ${ }^{\circ} \mathrm{C}$ for this study) yields maintenance of the tribofilm between the abrasive surfaces and lower ACOFs are expected. As the fluid temperature increases $\left(75^{\circ} \mathrm{C}\right.$ and $100^{\circ} \mathrm{C}$ for this study), tribofilm formation becomes challenging. However, nano fluid pressure between the substrates increases depending on the sliding speed $(1 \mathrm{~m} / \mathrm{s}$ for this study). This augmented pressure reaches to adequate values to separate the surfaces and facilitates lower metal contact and wear. The lowest ACOF values were observed for $\mathrm{CuZnFe}_{2} \mathrm{O}_{4}$ nano oil ambient and this can be attributed to the highest viscosity of this nano oil compared to others. On the other hand, high temperatures expedite more nano particle to melt down and sinter the grooves on the surfaces (lower roughness and ACOF, polishing effect), that is, low ACOFs are attributed to the viscosity effect prevailing under lower temperatures. This situation is explained with rolling-polishing effects under higher temperatures. However, the results depicted that viscosity is much more effective than that of rolling and/or polishing effect in terms of ACOF reduction. Thus, lowest ACOF was observed for $\mathrm{CuZnFe}_{2} \mathrm{O}_{4}$ nano oil ambient at $50^{\circ} \mathrm{C}$. Variations of ACOFs with respect to experimental duration under various temperatures are shown in Figures 5-7.



Figure 5. ACOF vs. test duration $\left(@ 50^{\circ} \mathrm{C}\right)$.

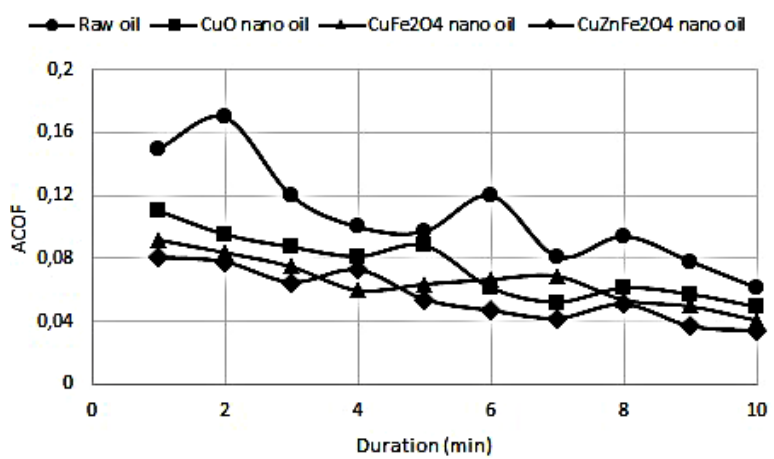

Figure 6. ACOF vs. test duration $\left(@ 75^{\circ} \mathrm{C}\right)$.

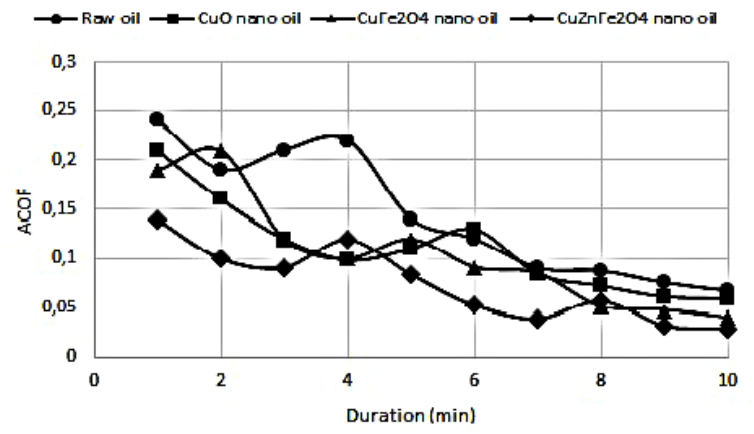

Figure 7. ACOF vs. test duration $\left(@ 100^{\circ} \mathrm{C}\right)$. 


\subsection{Wear Analysis}

Depth and width of the wear tracks formed on the specimen surfaces depend on the normal load and tribofilm formation between the surfaces. Thicker film leads to lower metal contact and wear. Furthermore, lubrication regimes have substantial importance in terms of tribofilm formation, polishing and rolling effects. SEM visualization of the wear tracks along the sliding direction under the load of $20 \mathrm{~N}$, sliding speed of $1 \mathrm{~m} / \mathrm{s}$ and temperature of $75^{\circ} \mathrm{C}$ is shown in Figure 8. The smoothest surface subsequent to friction analysis was facilitated in $\mathrm{CuZnFe}_{2} \mathrm{O}_{4}$ nano oil whereas the harshest was determined in raw oil. It was concluded that, all nano oil ambients provided lower wear track depths compared to that of the raw oil. However, the best results in the context of wear scratches were obtained for $\mathrm{CuZnFe}_{2} \mathrm{O}_{4}$ nano oil among the others. Nevertheless, lowest ACOF was also provided for the same nano oil ambient. Temperature increment had lower effect on $\mathrm{CuZnFe}{ }_{2} \mathrm{O}_{4}$ suspension due to its highest viscosity. Besides, high viscosity facilitated rapid fluid pressure increment and separation of the abrasive surfaces.

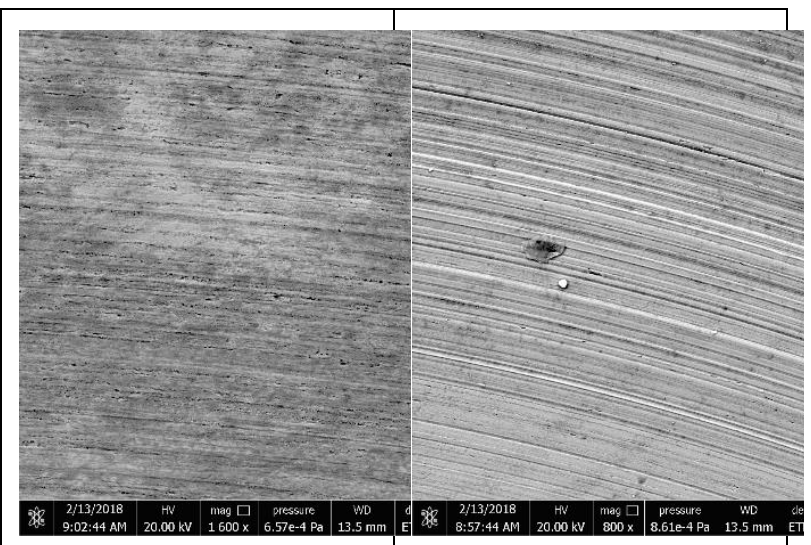

(a)

(b)

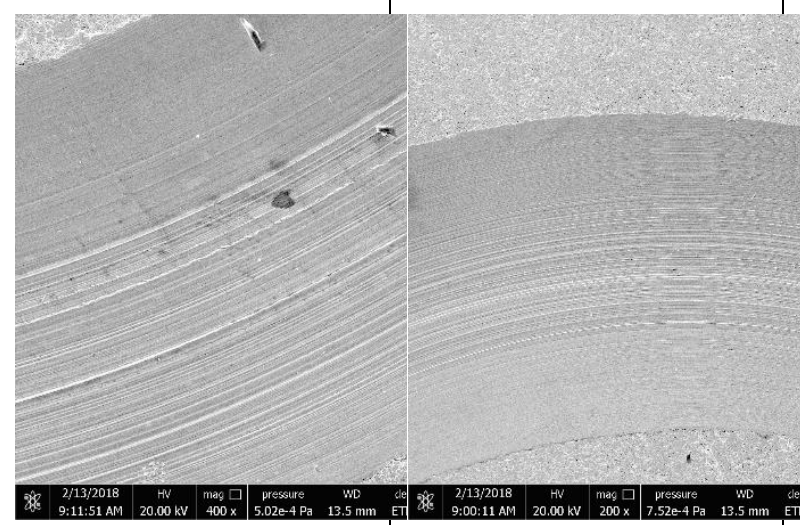

(c)

(d)

Figure 8. SEM visualizations of piston ring specimen surfaces (for $75^{\circ} \mathrm{C}$ ) in: (a) Raw oil, (b) $\mathrm{CuO}$ nano oil, (c) $\mathrm{CuFe}_{2} \mathrm{O}_{4}$ nano oil, (d) $\mathrm{CuZnFe}_{2} \mathrm{O}_{4}$ nano oil.

\subsection{Engine Power and CO Emission Analyses}

Frictional losses due to contact between moving parts consume $17-19 \%$ of the total power generated by the engine [22, 8, 23]. On the other hand, piston ring-cylinder liner assembly constitutes $40-50 \%$ of these total frictional losses [22, 8, 24]. Thus, tribological improvement in a fired engine is imperative in order to enhance engine power and reduce $\mathrm{CO}$ emissions. Due to the best tribological performance of $\mathrm{CuZnFe}_{2} \mathrm{O}_{4}$ nano particle, the highest engine power (Figure 9) and the lowest $\mathrm{CO}$ emissions (Figure 10) were obtained for this suspension. Low friction provided by $\mathrm{CuZnFe}_{2} \mathrm{O}_{4}$ nano oil yielded engine to produce more power (in average) than that of the other lubricants for the same engine speed. Also, reduced friction led to reduced heat loss from the combustion chambers and more power generation within unit time. Furthermore, low wear leads to longer engine life. In terms of engine power, an average increment of $15 \%$ was obtained with $\mathrm{CuZnFe}_{2} \mathrm{O}_{4}$ compared to that of the raw oil.

Incomplete in-cylinder combustion in a diesel engine causes high-level $\mathrm{CO}$ emissions. Low combustion efficiency leads to more fuel to be injected to generate the same power compared to that of better combustion characteristics. More fuel injection brings about more carbon entrainment into the cylinder and increased $\mathrm{CO}$ emissions. Therefore, less fuel introduction is crucial in the context of $\mathrm{CO}$ emission reduction for the same engine speed. Because the lowest friction values were obtained for $\mathrm{CuZnFe}_{2} \mathrm{O}_{4}$ nano oil, lowest $\mathrm{CO}$ emissions were also obtained, that is, due to low friction, the crank mechanism was able to run smoother and necessitated lesser fuel consumption and thus, lower carbon introduction into the cylinders. This phenomenon led to an average $\mathrm{CO}$ reduction of $18 \%$ for $\mathrm{CuZnFe}_{2} \mathrm{O}_{4}$ nano oil compared to that of the raw oil.

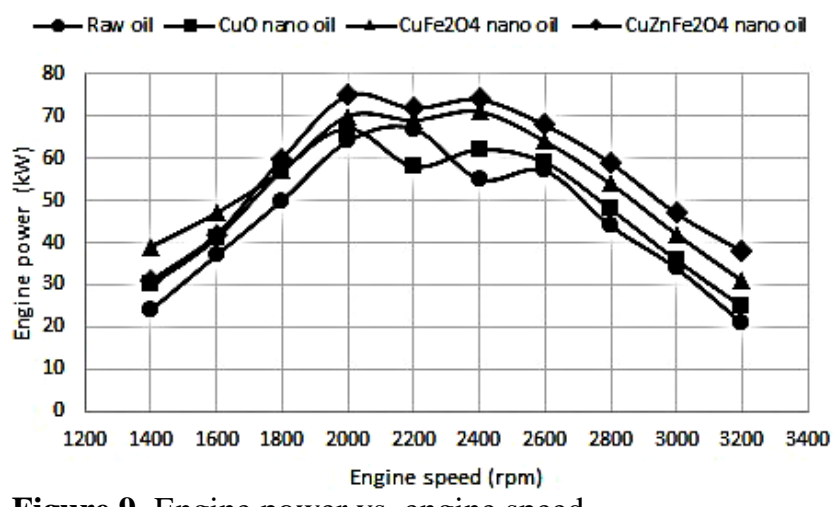

Figure 9. Engine power vs. engine speed. 


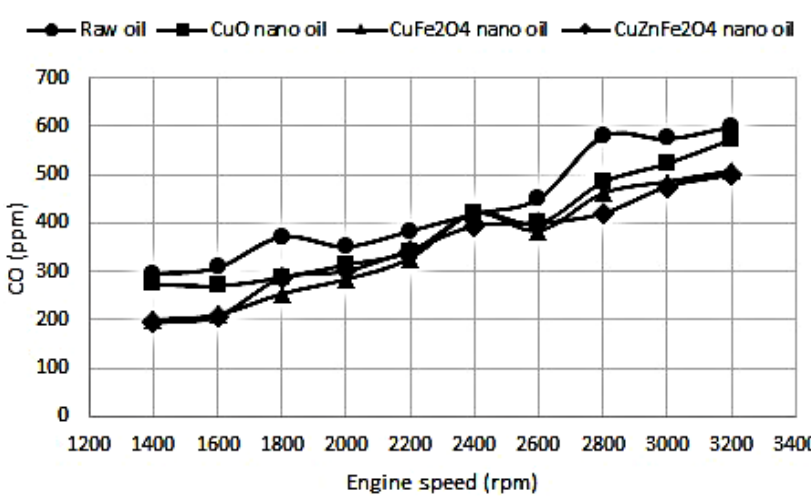

Figure 10. CO emissions vs. engine speed.

\section{Conclusion}

In this study, it was depicted that nano particle incorporated engine oil demonstrates better tribological characteristics than that of the standard engine oil. Enhanced tribological performance also facilitated better engine performance and $\mathrm{CO}$ emission reduction characteristics. It was concluded that, friction reduction capacity of a lubricant is strongly dependent on the lubricant temperature and viscosity especially under low temperatures. Viscosity was more effective than that of rolling and polishing effects under lower temperatures in terms of tribofilm formation on the substrates. Temperature increment causes viscosity reduction and worsens maintenance of the tribofilm. However, high temperatures facilitate more nano particle melt down and fill the cracks on the surfaces. Reduced friction yields more power generation and lower $\mathrm{CO}$ emissions due to diminished fuel injection for the same engine power and speed. Consequently, $\mathrm{CuZnFe}_{2} \mathrm{O}_{4}$ nano oil depicted the best tribological, engine performance and emission characteristics among the others. This additive can be a good candidate for diesel engine lubricants.

\section{Acknowledgement}

The author would like to thank Çukurova University, Adana Vocational School of Higher Education, TEMSA Laboratories and Hitit University, Scientific Technical Application and Research Center for their support in conducting this study.

\section{Ethics}

There are no ethical issues after the publication of this manuscript.

\section{References}

1. Lee, K, Hwang, Y, Cheong, S, Choi, Y, Kwon, L, Lee, J, Kim, S.H 2009. Understanding the role of nanoparticles in nano-oil lubrication. Tribology Letters; 35(2): 127-131.

2. Liu, G, Li, X, Qin, B, Xing, D, Guo, Y, Fan, R. 2004. Investigation of the mending effect and mechanism of copper nano-particles on a tribologically stressed surface. Tribology Letters; 17(4): 961-966.

3. Tao, X, Jiazheng, Z, Kang, X. 1996. The ball-bearing effect of diamond nanoparticles as an oil additive. Journal of Physics D: Applied Physics; 29(11): 2932-2937.

4. Padgurskas, J, Rukuiza, R, Prosyčevas, I, Kreivaitis, R. 2013.
Tribological properties of lubricant additives of $\mathrm{Fe}, \mathrm{Cu}$ and $\mathrm{Co}$ nanoparticles. Tribology International; 60: 224-232.

5. Tarasov, S, Kolubaev, A, Belyaev, S, Lerner, M, Tepper, F. 2012. Study of friction reduction by nanocopper additives to motor oil. Wear; 252(1-2): 63-69.

6. Yu, H, Xu, Y, Shi, P.J, Xu, B.S, Wang, X.L, Liu, Q, Wang, H.M 2008. Characterization and nano-mechanical properties of tribofilms using $\mathrm{Cu}$ nanoparticles as additives. Surface and Coatings Technology; 203(1-2): 28-34.

7. Choi, Y, Lee, C, Hwang, Y, Park, M, Lee, J, Choi, C, Jung, M. 2009 Tribological behavior of copper nanoparticles as additives in oil. Current Applied Physics; 9(2): 124-127.

8. Ali, M.K.A, Xianjun, H, Mai, L, Bicheng, C, Turkson, R.F, Qingping, C. 2016. Reducing frictional power losses and improving the scuffing resistance in automotive engines using hybrid nanomaterials as nano-lubricant additives. Wear; 365, 270-281.

9. Padgurskas, J, Rukuiza, R, Prosyčevas, I, Kreivaitis, R. 2013. Tribological properties of lubricant additives of $\mathrm{Fe}, \mathrm{Cu}$ and $\mathrm{Co}$ nanoparticles. Tribology International; 60: 224-232.

10. Ali, MKA, Fuming, P, Younus, HA, Abdelkareem, MAA, Essa, FA, Elagouz, A, Xianjun, H. 2018. Fuel economy in gasoline engines using $\mathrm{Al}_{2} \mathrm{O}_{3} / \mathrm{TiO}_{2}$ nanomaterials as nanolubricant additives. Applied Energy; 211: $461-478$

11. Suryawanshi, SR, Pattiwar, JT. 2018. Effect of $\mathrm{TiO}_{2}$ nanoparticles blended with lubricating oil on the tribological performance of the journal bearing. Tribology in Industry; 40(3): 370-391.

12. Zin, V, Agresti, F, Barison, S, Colla, L, Gondolini, A, Fabrizio, M 2013. The synthesis and effect of copper nanoparticles on the tribological properties of lubricant oils. Nanotechnology; 12: 751-759.

13. Bi, S, Guo, K, Liu, Z, Wu, J. 2011. Performance of a domestic refrigerator using $\mathrm{TiO}_{2}-\mathrm{R} 600 \mathrm{a}$ nano-refrigerant as working fluid. Energy Conversion Management; 52: 733-737.

14. Xing, M, Wang, R, Yu, J. 2014. Application of fullerene C60 nanooil for performance enhancement of domestic refrigerator compressors, International Journal of Refrigeration; 40: 398-403.

15. Podgornika, B, Vizintina, J, Jacobsonb, S, Hogmarkb, S. 2004 Tribological behaviour of WCyC coatings operating under different lubrication regimes. Surface and Coatings Technology; 177-178: 558565

16. Ali, MKA, Fuming, $\mathrm{P}$, Younus, HA, Abdelkareem, MAA, Essa, FA, Elagouz, A, Xianjun, H. 2018. Fuel economy in gasoline engines using $\mathrm{Al}_{2} \mathrm{O}_{3} / \mathrm{TiO}_{2}$ nanomaterials as nanolubricant additives. Applied Energy; 211: 461-478.

17. Ali, MKA, Xianjun, H, Abdelkareem, MAA, Gulzar, M, Elsheikh, AH. 2018. Novel approach of the graphene nanolubricant for energy saving via antifriction/ wear in automobile engines. Tribology International; 124: 209-229.

18. ASTM D-445, Standard test method for kinematic viscosity of transparent and opaque liquids, American Society for Testing and Materials. https://www.astm.org/Standards/D445 (accessed at 15.04.2018).

19. Zhang, S, Hu, L, Feng, D, Wang, H. 2013. Anti-wear and frictionreduction mechanism of $\mathrm{Sn}$ and $\mathrm{Fe}$ nanoparticles as additives of multialkylated cyclopentanes under vacuum condition. Vacuum; 87: 75-80.

20. Arumugam, S, Sriram, G. 2013. Preliminary study of nano- and microscale $\mathrm{TiO}_{2}$ additives on tribological behavior of chemically modified rapeseed oil. Tribology Transactions; 56(5): 797-805. 
Celal Bayar University Journal of Science

Volume 15, Issue 3, 2019, p 251-256

Doi: $10.18466 /$ cbayarfbe. 453763

AC. Yilmaz

21. Krishna Sabareesh, R, Gobinath, N, Sajith, V, Das, S, Sobhan, C. B. 2012. Application of $\mathrm{TiO}_{2}$ nanoparticles as a lubricant-additive for vapor compression refrigeration systems: an experimental investigation. International Journal of Refrigeration; 35(7): 19891996.

22. Ali, M.K.A, Xianjun, H. 2015. Improving the tribological behavior of internal combustion engines via the addition of nanoparticles to engine oils. Nanotechnology Reviews; 4(4): 347-358.
23. Ali, M.K.A, Xianjun, H, Turkson, R.F, Ezzat, M. 2015. Analytical study of tribological parameters between piston ring and cylinder liner in internal combustion engines. Proceedings of the Institution of Mechanical Engineers, Part K: Journal of Multi-body Dynamics; 230(4): 329-349.

24. Blau, P.J. 2001. A review of sub-scale test methods to evaluate the friction and wear of ring and liner materials for spark and compression ignition engines. National Laboratory Technical Report, Tennessee, USA. 